Columbia Business School
Center on Japanese Economy and Business

CENTER ON JAPANESE ECONOMY AND BUSINESS

日本经济经営研究所

Working Paper Series

April 2015, No. 341

\title{
Absence of Safe Assets and Fiscal Crisis
}

Masaya Sakuragawa and Yukie Sakuragawa

COLUMBIA UNIVERSITY IN THE CITY OF NEW YORK 


\title{
Absence of Safe Assets and Fiscal Crisis*
}

\author{
Masaya Sakuragawa (Keio University) ${ }^{*}$ \\ Yukie Sakuragawa (Atomi University) ${ }^{* *}$
}

\begin{abstract}
This paper provides a fiscal crisis model that explains the low interest rates of Japanese government bonds. The key ingredient is the absence of safe assets in the sense that investors have no access to any asset that hedges fiscal risk. The interest rate is insensitive to any change in fiscal conditions and does not fully reflect the risk premium. This finding explains the low interest rates of Japanese government bonds even though the risk of fiscal default looks fairly high. The poorly-functioning bond market created in this way contributes to the low interest rate followed by a low default probability, and allows the government to sustain its large debt. This finding explains the mechanism under which the low interest rate coexists with Japan's large outstanding debt. Welfare implications are mixed. The well-functioning bond market does not always contribute to welfare enhancement because the market makes it difficult to sustain the debt. We show the implications for fiscal sustainability of some policies, such as financial market reforms and growth enhancement policies.
\end{abstract}

Keywords: fiscal crisis, safe asset, risk premium, sustainability

JEL: E00, G12, H63

\footnotetext{
*The main idea of this paper was inspired when both of us stayed at the CJEB as visiting researchers. We are grateful to Shin-ichi Fukuda, Chen-Min Hsu, Young-Jae Kim, Takashi Niizato, Etsuro Shioji and participants of the meetings of the Asia-Pacific Economic Association and of the Japanese Economic Association and of the seminar held in Hitotsubashi University for valuable and insightful comments and discussions.

* Masaya Sakuragawa, Keio University, 2-15-45 Mita, Minato-ku, Tokyo Japan 108-8345, (tel \& fax) 81-03-5427-1832, (e-mail) masaya@ keio.econ.ac.jp

** Yukie Sakuragawa, Atomi University, 1-9-6, Nakano, Niiza-shi, Saitama Japan 352-8501, sakuraga@atomi.ac.jp
} 


\section{Introduction}

The Japanese economy bears significant fiscal burdens. The outstanding government debt is enormous, over two hundred percent as a proportion of GDP. Figure 1 illustrates the cross-country comparison for the nominal interest rate and the government debt to GDP ratio in the OECD countries, suggesting a puzzling fact. Japan looks an outliner; the interest rate is the lowest, but the debt to GDP ratio is the highest. An open question is why the low interest rate coexists with the large outstanding debt.

(Insert Figure 1)

The government bond is typically thought of as one of safest assets, but falls into a risky asset when the fiscal crisis is likely to occur. If investors have easy access to foreign markets, some foreign safe asset is used for an anchor to price the government bond, but otherwise, what asset will be an anchor? Investors often find it difficult to access to foreign markets due to capital controls, the foreign exchange risk, and/or the lack of skill to deal with foreign portfolio. What makes things difficult will be the fact that returns on private assets also fall on the onset of the fiscal crisis. For example, Reinhalt and Rogoff (2010), in their 224 observations for domestic crises, document that the cumulative output declines around the period of a domestic debt crisis are significant, amounting to 8 percent on average. ${ }^{1}$ Investors of this closed economy fall into a situation of the absence of any safe asset in the sense that they have no access to any asset that hedges the fiscal risk.

Some observations support the view that the Japanese government bond (JGB) market is isolated from foreign markets. Figure 2 depicts the nominal returns on the 10 year government bond for four countries, all of which are denominated by their own currencies. The returns on the US, the UK, and Germany are almost close over the period 1999-2014, but the return on Japan is apart from them and is persistently low, suggesting that the JGB market is isolated from other markets. ${ }^{2}$

\section{(Insert Figure 2)}

Domestic investors hold almost 95 percent of the debt outstanding. This number is extremely higher than foreign countries. For example, domestic investors of the US hold

\footnotetext{
1 They argue on fiscal crises by separating external and domestic debt crises. The comparable average output decline for external debt events is only 2.6 percent.

${ }^{2}$ If the nominal exchange rate follows a martingale, no arbitrage condition requires nominal returns on the government bond to be equal.
} 
49 percent and domestic investors of the UK hold 69 percent of the outstanding debt. ${ }^{3}$ Additionally, behind this strong home bias for government bonds, several large bondholders are financial institutions that are owned or regulated by the government and perceived to have limited access to foreign markets for various reasons, such as regulations and the misguided governance. ${ }^{4}$ Indeed, if they had easy access to foreign markets, they should have requested any higher return on the JGB than is illustrated in Figure 2. We state details of some features of the JGB market in Appendix 1.

The aim of this paper is to understand the behavior of the government bond market and fiscal sustainability when there is the absence of safe assets. We identify this situation as a model of closed economy in which investors can access to two domestic assets, the government bond and private capital, whose return falls on the occurrence of the fiscal crisis. The key ingredient in the model is the absence of any safe asset in the sense that investors have no access to any asset that hedges the fiscal risk.

When there is an asset that hedges the fiscal risk, the standard argument of asset pricing is applied; the interest rate on government bonds reflects fully the default risk (e.g., Uribe 2006). However, when there is no any asset that hedges the fiscal risk, the interest rate is insensitive to the change in the fiscal conditions, and does not fully reflect the default risk. This is because when the fiscal default occurs, the return on the government bond declines, and at the same time the opportunity cost of holding the bond declines. This mechanism explains low interest rates of Japanese government bonds although the risk of fiscal default looks fairly high.

When the government bond market functions poorly, the low interest rate is followed by the low default probability even under serious fiscal conditions, and the government is allowed to sustain the large debt. This finding explains the mechanism under which the low interest rate coexists with the large outstanding debt in Japan. Additionally, this finding suggests that the current low interest rate does not reflect any soundness of fiscal conditions, but rather would be a bad signal of the enormous damages of the fiscal default.

\footnotetext{
${ }^{3}$ The data source is OECD.

${ }^{4}$ An ever growing number of studies investigate the determinants of home bias from both rational and behavioral perspectives. The determinants proposed by those studies include transaction costs (Glassman and Riddick, 2001), real exchange rate risks (Fidora, Fratzscher and Thimann, 2007), information barriers (Ahearne, Griever and Warnock, 2004), corporate governance issues (Dahlquist, Pinkowitz, Stulz and Williamson, 2003), lack of familiarity (Portes and Rey, 2005), to name a few.
} 
People may still feel safe for the fiscal conditions with the low interest rate, but the fiscal default can occur suddenly before the interest rate goes up. Policymakers need to understand the mechanism behind the low interest rate.

The concern is to understand how the functioning of the government bond market influences the welfare. The well-functioning bond market does not always contribute to the enhancement of the welfare because at the same time it makes it difficult to sustain the debt. When the outstanding debt is already large, agents are rather better off thanks to financial repression.

The welfare analysis provides interesting implications of policies, such as financial market reforms and growth enhancement policies. These policies are, in principle, welfare enhancing, and at the same time pull up the interest rate and make debt sustainability difficult. Implementing reforms needs careful procedures from the viewpoint of macro prudence. It is dangerous to implement reforms while keeping the debt level intact.

This paper is related to much literature that provides the pessimistic scenario for the fiscal sustainability in Japan. The literature includes Doi and Ihori (2003), Dekle (2005), Broda and Weinstein (2005), Ihori et al. (2007), Sakuragawa and Hosono (2010, 2011), Doi, Hoshi, and Okimoto (2011), Hoshi and Ito (2013), Hansen and Imrohoroglu (2014), and others.

Among them, closely related are papers that attempt to explain low interest rates on government bonds in general equilibrium models. Sakuragawa and Hosono $(2010,2011)$ provide a growing economy in which financial repression can lead to the reduction of the interest rate and contribute to the sustainability by incorporating intermediation costs into the model. Hansen and Imrohoroglu (2013) provide a model of the bond in the utility in order to explain the low rate.

The literature that focuses on external debt in emerging countries highlights the government's strategic default (e.g., Calvo 1988, Arellano 2008, and others). By contrast, this paper focuses on domestic debt of an economy in which domestic residents hold almost all the debt so that the strategic default is a relatively small concern.

There are several papers that try to explain overvaluations of asset prices or bubbles. Harrison and Kreps (1978) and Scheinkman and Xiong (2003) explain that heterogeneous beliefs generated by people's overconfidence, with short-sale constraints, can cause the bubble component in asset prices. De Long et al. (1990) and Abreu and Brunnermeier 
(2003) explain that rational investors have an incentive to exploit arbitrage opportunities when the asset is mispriced, thereby allowing the overvaluation of prices relative to fundamentals to persist for some periods. Our finding is contrasted with theirs because the seemingly overvalued bond price is never attributed to any heterogeneity in belief nor short-sale constraints.

This paper is organized as follows. In Section 2 we set up a model of fiscal crisis. In Section 3 we characterize the equilibria of the model. In Section 4 we check the generality of the developed model by introducing some investors who access to foreign safe asset. In Section 5 we show several features in our model by some comparative statics and welfare analysis. In Section 6 we provide some policy implications. In Section 7, we conclude.

\section{A Model of Fiscal Crisis}

The basic structure of the model follows Romer (2001, Ch.11). There are two periods: period 0 and period 1, and two types of agents: investors (=consumers) and the government. Investors are endowed with $W_{0}$ in period 0 and $W_{1}$ in period 1 , and derive the utility from the government expenditure $G$ in period 0 and consumption $C_{1}$ in period 1 . Their preference is given by $u(G)+C_{1}$, where $u($.$) is increasing and concave for G>0$. Given $G$, in period 0 investors save the income by investing in capital $K$ that yields the return next period and the one-period bond $D$ issued by the government. In period 1 they receive returns from the investment and the income $W_{1}$, pay tax $T$, receive the transfer, and consume the remaining.

In period 0 the government finances the lumpy expenditure $G$ by issuing the one-period bond $D(=G)$ with a (gross) interest rate $R$ that is payable unless the government defaults on debt. In period 1 the government receives tax, pays the interest rate, and pays back the transfer. The government behaves by maximizing the investor's welfare. There is no conflict of interest between them. As stated later, all the bonds are held by investors who are domestic citizens, and so the government has no incentive to do strategic default to them. The unique choice of the government is the decision for financing the expenditure or not.

The tax $T$ is stochastic and follows the cumulative distribution function $F(T)$ that 
is continuously differentiable with a positive density $f$ over $[\underline{T}, \bar{T}]$. The government defaults if and only if $T$ is less than some threshold $T^{*}$ that satisfies $R D=T^{*}$. Letting $\tau(T)$ denote the transfer that is a function of $T$, the budget constraints of the government is written as $G=D$ in period 0 and $\tau(T)+R D=T$ in period 1. We assume the following transfer rule; (i) $\tau(T)=T$ if $T<T^{*}$ and (ii) $\tau(T)=T-T^{*}$ if $T \geq T^{*}$. The first rule says that if the government defaults on the debt, the tax is returned back to taxpayers. ${ }^{5}$ The second rule says that if the government does not default on the debt, the surplus of the tax necessary for paying off the debt $\left(T-T^{*}\right)$ is returned back to taxpayers. ${ }^{6}$

We express the default cost as the decline in the productivity; the return on capital is $A$, but once the fiscal default occurs, it drops down to $(1-\theta) A$, with $0 \leq \theta \leq 1$. This element is the key ingredient that leads to main findings that follow. ${ }^{7}$ Since the risk is perfectly correlated between capital and the bond in the default state, $\theta$ captures also the degree to which capital does not hedge fiscal risk. We can think of $\theta$ as no risk hedge measure.

The output decline occurs in several ways. When short-term bonds are used as collateral for the repo transaction among banks, the fiscal default leads to the shortage of liquidity in the interbank market, followed by the contraction of economic activities. As the fiscal theory of the price level suggests, the fiscal crisis gives the inflationary pressure and turn the economy into turmoil. Banks holding huge government bonds deteriorate their balance sheets and have to shrink lending to private sectors.

Finally, we impose the following assumption.

\footnotetext{
${ }^{5}$ Under this rule, we exclude the possibility of partial default. An alternative way is to consider the case for the partial default when the repayment on the default state depends on $T$, but then the calculation becomes troublesome without getting anything value-added.

${ }^{6}$ Alternatively, we can describe the evaluation of public debt in terms of the price. Suppose that the government expenditure $G$ is to be financed by issuing $D$ units of public debt with the matured price being unity. Letting the price of public debt denote $p$, the government budget constraint in period 0 requires $G=p D$. A threshold level tax $T^{*}$ can feature the budget constraint in period 1: $G / p=T^{*}$.

${ }^{7}$ Cohen and Sachs (1986), Cole and Kehoe (2000), and Arellano (2008) also model fiscal default costs as having negative implications on output.
} 
Assumption $1 \lim _{G \rightarrow 0} u^{\prime}(G)>A+\theta A^{2} W_{0} f(0)$

This assumption guarantees that the government that aims to maximize the investor's welfare chooses to issue the bond.

Table 1 summarizes returns on the government bond and capital.

Table 1: Returns on government bond and capital

\begin{tabular}{|c|c|c|}
\hline & Non-default state & Default state \\
\hline Government bond & $R$ & 0 \\
\hline Capital & $A$ & $(1-\theta) A$ \\
\hline
\end{tabular}

The economy is a closed economy because investors can have no access to foreign safe assets. Later we relax the model by allowing for investors that have access to foreign markets.

\section{Equilibria}

From the assumption on the distribution on tax, the probability of default is the probability that $T$ is less than $R D\left(=T^{*}\right)$. We can write the default probability as

$$
\pi=F(R D)
$$

The set of points satisfying (1), that we call the government condition hereafter, is plotted in the $(R, \pi)$ space in Figure 3. The locus is horizontal at $\pi=0$ below $R<\underline{T} / D$, upward-sloping at the range of $\underline{T} / D<R<\bar{T} / D$, and horizontal at $\pi=1$ above $\bar{T} / D<R$. If we assume $\underline{T} / D<A$, the fiscal default will certainly occur with positive probability. We proceed with the analysis by imposing this assumption. If the density function is bell-shaped, the distribution function has an $S$ shape like that shown in the figure. The government repays the debt obligation $R D$ with probability $1-\pi$, while it defaults on debt with probability $\pi$.

(Insert Figure 3) 
If investors would hold the government bond, they should be indifferent between capital and the bond. The no arbitrage condition is written as

$$
(1-\pi) R=(1-\pi) A+\pi(1-\theta) A
$$

if $D>0$. The LHS is the expected return on the government bond; investors receive the payment only if the fiscal policy is sustainable. The RHS is the expected return on capital; investors receive $A$ if the fiscal policy is sustainable, and $(1-\theta) A$ otherwise. The distinguishable feature is that the fiscal default gives a negative externality on the return on capital. This market condition fully reflects the information on the investor's behavior of utility maximization because all that investors can do is to allocate their savings between capital and the bond.

Rearranging (2) yields the equation for the determination of the interest rate:

$$
R=A+\frac{\pi}{1-\pi}(1-\theta) A
$$

The first term of the RHS captures the riskless part of return and the second the risk premium. As $\theta$ is high, the risk premium is smaller, and the interest rate is less likely to reflect the risk premium fully. This is because when the fiscal default occurs, the return on the government bond declines and at the same time the opportunity cost of holding the bond also declines. At the extreme when $\theta=1$, the interest rate never reflects the risk premium: $R=A$. Note that when $\theta=0$, (3) reduces to the standard expression: $R=A /(1-\pi) ;$ the interest rate fully reflects the risk premium.

We turn to the formal analysis. We use (1) and (2) to define the net return function on the government bond. Formally,

$$
\Omega(R) \equiv R\{1-F(R D)\}-A\{1-\theta F(R D)\},
$$

for $0 \leq \theta<1 .^{8}$ The first term is the expected return on the bond and the second the

\footnotetext{
${ }^{8}$ We exclude the case for $\theta=1$. When $\theta=1, \Omega(R) \equiv(R-A)\{1-F(R D)\}$ holds. Then $\Omega(R)=0$
} 
expected return on capital. We maintain one technical assumption for the functional form on $f($.$) to simplify the analysis without losing any qualitative properties.$

Assumption 2: $\quad 2 f(R D)+f^{\prime}(R D)(R D-\theta A D)>0$ for any $R D>0$

This assumption allows $\Omega(R)$ to be concave. ${ }^{9}$ As Figure 4 illustrates, this function is first increasing, later reaches the peak, and is finally decreasing over the interval $(\underline{T} / D,+\infty)$.

(Insert Figure 4)

Letting $\hat{R}$ denote the interest rate that maximizes $\Omega(R)$, there are two interest rates that intersect the horizontal line when $\Omega(\hat{R})>0$. The lower interest rate $R^{E}$ is stable and the higher one $R^{F}$ is unstable. Suppose that the interest rate is slightly below $R^{F}$. At this point, the expected return on bond is higher than the expected return on capital. Then investors will increase the demand for bond and the interest rate starts to fall. This process continues until $R^{E}$ is reached. A similar argument holds if the interest rate is slightly above $R^{F}$ so that the expected return on the bond is lower than the expected return on capital. Then investors will decrease the demand for bond and the interest rate rises further. This process continues until no investors purchase the bond at any interest rate. Thus there is another stable equilibrium in which $R$ approaches an infinity. The argument is summarized in the following.

Proposition 1: Suppose that $\Omega(\hat{R})>0$, where $\hat{R}=\operatorname{argmax} \Omega(R)$ so that there exists an equilibrium where investors are willing to hold the government bond. When $\underline{T} / D<A$ and $0 \leq \theta<1$, there are two stable equilibria and one unstable equilibrium.

For reference, we reformulate equilibria in the $(R, \pi)$ space following Romer (2001). Equation (2) is rewritten as

if and only if $R=A$.

9 This assumption guarantees the global concavity of this function, but strictly speaking, the local concavity always holds and sufficient. But without this assumption, the number of equilibria may exceed five, and the analysis will be so troublesome. 


$$
\pi=\frac{R-A}{R-\theta A}
$$

$R>\theta$ A should hold; otherwise in (2) the LHS should be always higher than the RHS, which is impossible. The locus of points satisfying (5) is plotted in the $(R, \pi)$ space in Figure 5. When the government always make payments on debt (that is, when $\pi=0$ ), $R$ equals $A$. As the probability of default goes up, the interest rate the government must offer rise; thus the locus is upward-sloping. Finally $R$ approaches infinity as the probability of default approaches one. Three cases are depicted for different $\theta$ 's.

(Insert Figure 5)

Equilibria are shown by the two loci of the government condition (1) and the market condition (5), as depicted in Figure 6. For $0 \leq \theta<1$, at $R=\bar{T} / D$, the locus (1) should be always above the locus (5). Given the assumption of $\underline{T} / D<A$, both loci intersect twice whenever they do. ${ }^{10}$

There are three equilibria. The equilibrium which corresponds to the lower interest rate $R^{E}$ is the point $E$, where the equilibrium is stable and the probability of default is low. The equilibrium which corresponds to the higher interest rate $R^{F}$ is the point $F$, where the equilibrium is unstable. Another stable equilibrium approaches to the pair $(R, \pi)=(+\infty, 1)$, where the default is certain and investors refuse to hold the government bond. We hereafter call the equilibrium at $E$ the good equilibrium and the other stable equilibrium the bad equilibrium.

\section{(Insert Figure 6)}

Each of the two stable equilibria is self-fulfilling. If investors believe that the probability of default should be low at the good equilibrium, the interest rate which realizes at the market is low and the equilibrium is stable. On the other hand, if investors believe that the probability of default must be very high at the bad equilibrium, investors do not hold the bond at any interest rate, which brings the default immediately. As the result, the bad equilibrium is also stable. In short, the investors' expectation of the probability of default decides which equilibrium realizes.

${ }^{10}$ When $\theta=1$, the locus (1) never goes across the locus (5) from below. 


\section{Features of the Model}

We investigate several features of this model. Consider the effects of the debt $D$ and the no risk hedge measure $\theta$ on the interest rate $R^{E}$ and the default probability $\pi$. We first focus on the analysis at the good equilibrium, and later extend the analysis to include the region where the good equilibrium is not supported.

Figure 7 shows the effects of a change in the debt $D$. An increase in $D$ from $D_{0}$ to $D_{1}$ shifts curve (1) upwardly. The interest rate and the default probability go up at the good equilibrium. We summarize this standard result as follows.

Proposition 2: As the debt $D$ goes up, the interest rate and the default probability increase at the good equilibrium.

Proof: See the Appendix 2.

(Insert Figure 7)

Figure 8 illustrates the effects of a change in $\theta$. As $\theta$ goes up, the curve (5) shifts upwardly. The interest rate and the default probability decline at the good equilibrium.

Proposition 3: As the no risk hedge measure $\theta$ goes up, the interest rate and the default probability decline at the good equilibrium.

Proof: See the Appendix 2.

When $\theta$ is high, the interest rate does not reflect the risk premium. This is because when the fiscal default occurs, the return on the government bond declines, and at the same time the opportunity cost of holding the bond declines. This mechanism explains low interest rates of Japanese government bonds although the risk of fiscal default looks fairly high.

(Insert Figure 8)

A puzzle in the Japanese government bond market is that an increase in the government debt does not lead to the interest rate hike. We next investigate conditions under which the interest rate is insensitive to the change in fiscal conditions. We defines sensitivity by the debt elasticity of interest rate $\frac{d \log R}{d \log D}\left(\equiv \frac{d R}{d D} \cdot \frac{D}{R}\right)$. 
Proposition 4: The sensitivity of a change in the debt $D$ to the interest rate is smaller as $\theta$ is high, if $f^{\prime}(.) \geq 0 .{ }^{11}$

Proof: See the Appendix 3.

When $\theta$ is high, the interest rate is insensitive to the change in fiscal conditions. Some observers criticize the low sensitivity of the interest rate in the Japanese bond market, but together with the finding in Proposition 3, we have to understand the tradeoff between the sensitivity and the level of the interest rate. If we hope for the sensitive market to be sensitive to shocks, we have to accept the high interest rate.

Summarizing up, the government bond market functions poorly in the sense that the interest rate does not reflect the risk premium nor is sensitive to the change in fiscal conditions.

We have focused on properties around the good equilibrium. Figure 7 suggests that there is some threshold level of the debt above which the good equilibrium disappears; then the economy should plunge into the bad equilibrium. Here we investigate how threshold levels of the debt and the interest rate change as $\theta$ changes.

Proposition 5: As the no risk hedge measure $\theta$ goes up, the maximum debt supported by the good equilibrium is larger, but the maximum interest rate supported by the good equilibrium may be higher or lower.

Proof: The maximum interest rate $\hat{R}$ is characterized by the threshold interest rate when it satisfies $\Omega(\hat{R}, \theta, D)=0$ as well as $\Omega_{R}(\hat{R}, \theta, D)=0$, where $\Omega_{R} \equiv \partial \Omega(R, \theta, D) / \partial R$. Note that we use $\Omega(R, \theta, D)$ instead of $\Omega(R)$ for expositional convenience. As Figure 9 illustrates, the function $\Omega($.) is tangent on the horizontal line. Using the Envelope theorem, there exists a function $D=D(\theta)$ that satisfies $\Omega(\hat{R}, \theta, D(\theta))=0$, with $D^{\prime}(\theta) \equiv d D / d \theta=-\Omega_{\theta} / \Omega_{D}>0$. This establishes the first result.

Next, differentiating $\Omega_{R}(\hat{R}, \theta, D)=0$ totally and rearranging yield

11 This is not a necessary condition. Several classes of functions satisfy this condition. For example, the uniform distribution satisfies this condition. 


$$
d \hat{R}=-\frac{\Omega_{R \theta}}{\Omega_{R R}} d \theta-\frac{\Omega_{R D}}{\Omega_{R R}} D^{\prime}(\theta) d \theta,
$$

where $\Omega_{R j} \equiv \partial \Omega_{R} / \partial j$ for $j=\theta, D, R$. We have $\Omega_{R R}=-\left\{2 f(R D)+f^{\prime}(R D) D(R-\theta A)\right\} D<0$ from Assumption, $\Omega_{R \theta}=A D f(R D)>0$, and $\Omega_{R D}=-\left\{2 f(R D)+f^{\prime}(R D) D(R-\theta A)\right\} R+\theta A f(R D)$. The first term of the RHS is positive, and the second term is uncertain; the total effect is uncertain. This establishes the second result. Q.E.D.

\section{(Insert Figure 9)}

The poorly-functioning government bond market captured by high $\theta$ contributes to fiscal sustainability; it leads to the low interest rate followed by the low default probability, and allows the government to sustain the large debt. This finding explains the mechanism under which the low interest rate coexists with the large outstanding debt in Japan. Additionally, this finding suggests that the current low interest rate does not reflect any soundness of fiscal conditions, but rather would be a bad signal of the enormous damages of the fiscal default.

To which direction the sustainable interest rate moves is ambiguous. There are two opposing effects. An increase in $\theta$ can enhance the maximum interest rate directly, but at the same time it can increase the sustainable debt and thus repress the maximum interest rate. Fortunately, we have a clear-cut finding by specifying the distribution function for tax.

Proposition 6: Suppose that the default probability is specified by a uniform distribution, that is, $F(R D)=R D / \bar{T}$ over $[0, \bar{T}]$. As $\theta$ is high, the maximum interest rate supported by the good equilibrium is lower.

Proof: See the Appendix 4. 
Strictly, we have $\frac{\partial \hat{R}}{\partial \theta}=\frac{-A}{\sqrt{(2-\theta)^{2}-\theta^{2}}}<0$ for $0 \leq \theta<1 .{ }^{12}$ The large sustainable debt and the low sustainable interest rate coexist. The fiscal default may occur suddenly at the timing when people still feel safe with the modest interest rate. Unless policymakers understand the mechanism behind the low interest rate, the economy should be a boiled frog!

\section{Welfare analysis}

We turn to the welfare analysis. We write the investor's expected utility as

(6) $u(G)+R\{1-F(R D)\} D+[\{1-F(R D)\}+(1-\theta) F(R D)] A K-\int_{R D}^{\bar{T}} R D f(T) d T+W_{1}$.

The first term is the utility from the government expenditure, the second term is the expected return on the bond, the third term is the expected return on capital, the fourth term is the period-1 endowment, and the last term is the expected tax payment. Note that the second and fourth terms cancel out, reflecting that all returns of the bonds accrue to domestic investors. We use $D+K=W_{0}, D=G$ and (2) to rewrite (6) as a function of $R$ and $D$ :

$$
V(R, D) \equiv u(D)+R\left(W_{0}-D\right)\{1-F(R D)\}+W_{1},
$$

which is first increasing, later reaches the peak, and is finally decreasing in terms of $R$, given $D$. We write the investor's welfare when the government does not issue the bond as $V^{\text {no_bond }}=A W_{0}+W_{1}$. Under Assumption 1, we have $V(R, D)>V^{\text {no_bond }}$ for some $R$.

We impose the following technical assumption to make the analysis simple without losing essential properties.

${ }^{12}$ In addition, we calculate the elasticity by $\frac{d \log \hat{R}}{d \log \theta}=\frac{\theta}{\hat{R}} \frac{\partial \hat{R}}{\partial \theta}=\frac{\sqrt{(2-\theta)^{2}-\theta^{2}}-(2-\theta)}{\sqrt{(2-\theta)^{2}-\theta^{2}}-2(1-\theta)}$. 
Assumption $3 u^{\prime}(G)=0$ for $G>\bar{G}$, where $\bar{G}$ is some positive constant.

Proposition 7: Suppose that Assumption 3 holds and that the economy lies at the good equilibrium. The welfare is decreasing in $\theta$, and first increasing and later decreasing in the outstanding debt $D .^{13}$

Proof: For the first part, it is sufficient to prove that, letting $R^{*}$ denote the interest rate that maximizes $V(R, D), R^{E}(\theta, D)$ lies less than $R^{*}$ so that the good equilibrium lies at some point around which $V(R, D)$ is increasing. As Figure 10 illustrates, $R^{E}(\theta, D)<\hat{R}$. Specially at $\theta=0, \arg \max \Omega(R)=\arg \max V(R, D)$, that is, $\hat{R}=R^{*}$. Thus at $\theta=0$, we see $R^{E}(0, D)<R^{*}$. In addition, $R^{E}(\theta, D)$ is decreasing in $\theta$ (Proposition 3 ): $R^{E}(\theta, D) \leq R^{E}(0, D)$ for any $0 \leq \theta<1$ and $D$. Therefore, we see that $R^{E}(\theta, D)<R^{*}$ for any $0 \leq \theta<1$.

For the second part, we rewrite the welfare function (7) as

$$
V(R(\theta, D), D)=u(D)+\{1-\theta \mathrm{F}(R(\theta, D) D)\} A\left(W_{0}-D\right)+W_{1} \cdot{ }^{14}
$$

The first term is increasing for $0<D<\bar{G}$, and the second term is decreasing in $D$. Note that $R(\theta, D)$ is increasing in $D$ at the good equilibrium (Proposition 2). Under Assumption 1, $V($.$) is increasing in D$ around $D=0$, but under Assumption 3, there is some level of debt above which $V($.$) is decreasing in D. Q.E.D.$

\section{(Insert Figure 10)}

Investors are better off as $\theta$ is low although the interest rate and the default probability are high. This arises from the fact that a high interest rate reflects a low deadweight loss accruing to capital holders. Investors gain from the high interest income more than lose from the high default probability. The well-functioning bond market contributes to enhance the investor's welfare so long as the debt is sustainable. On the other hand, the debt has a non-monotone effect on the welfare. Investors are better off as $D$ is high when the debt level is small, reflecting the high marginal utility from the public

\footnotetext{
${ }^{13}$ Assumption 3 is a sufficient condition to have this proposition. If $u^{\prime}(G)$ is positive but sufficiently small for large $G$, Proposition 7 tends to hold.

${ }^{14}$ Using (4) and $D=W_{0}-K$, we derive this equation.
} 
expenditure, but they are worse off as $D$ is high when the debt level is large, reflecting the cost of the high default probability.

We have examined the welfare when the good equilibrium is sustained. We investigate if the welfare is still monotone in $\theta$ when extending the analysis to include also the region where the good equilibrium is not sustained. Figure 11 illustrates the welfare function $\left.V\left(R\left(\theta^{j}, D\right), D\right)\right)$ in terms of the outstanding debt for different $\theta$ 's. Both functions are first increasing and later decreasing in $D$. Let $D\left(\theta^{j}\right)$ denote the threshold sustainable level of debt for $\theta^{j}(j=l, h)$, with $\theta^{l}<\theta^{h}$. As Proposition 5 shows, the maximum debt supported by the good equilibrium for $\theta^{l}$ is smaller than the one for $\theta^{h}$ : that is, $D\left(\theta^{l}\right)<D\left(\theta^{h}\right)$. If $D$ is smaller than $D\left(\theta^{l}\right)$, investors are better off as $\theta$ is low. However, once $D$ goes beyond $D\left(\theta^{l}\right)$, the government can still issue the bond for $\theta^{h}$, but cannot for $\theta^{l}$; in the latter the government gives up issuing the bond, and the welfare goes down to $V^{\text {no } b o n d}$. If the debt lies at the level of $D$ satisfying $D\left(\theta^{l}\right)<D<D\left(\theta^{h}\right)$, investors are rather better off at $\theta^{h}$ thanks to financial repression.

(Insert Figure 11)

We have investigated the expected welfare weighted over the default and non-default states. We briefly comment on the ex post welfare once the government defaults on the debt. As is straightforward, as the outstanding debt is large, the welfare goes down heavily. Combined with Proposition 5, an economy with poorly- functioning bond market can sustain the large debt followed by the low interest rate, but once the fiscal default occurs, this economy bears the large welfare loss, which arises through the large decline in the return on capital, and through the capital loss of the large debt.

\section{Robustness: Access to Foreign Markets}

We have thus far investigated the closed economy in which investors have no access to foreign markets. Here we extend the analysis to include investors who have access to foreign safe assets, and investigate to what extent the previous analysis is preserved.

Assume that the proportion $\varepsilon$ of investors are "unsophisticated" in the sense that they have no access to foreign assets as developed before, and the remaining proportion $1-\varepsilon$ are "sophisticated" investors who have access to foreign safe assets with a constant 
interest rate $1+r$. Assume further that sophisticated investors can afford to buy the total debt: that is, $D<(1-\varepsilon) W_{0}$, where $(1-\varepsilon) W_{0}$ is the aggregate wealth of sophisticated investors, which is the period-0 income multiplied by the proportion of sophisticated investors. Assume without loss of generality that $A=1+r$.

Sophisticated investors are willing to hold the government bond only if the interest rate satisfies

$$
(1-\pi) R=1+r(=A)
$$

i.e., the interest rate reflects the default risk fully. Equation (8) is interpreted as a special case of (2) when $\theta=0$. The crucial feature is that (2) and (8) never hold simultaneously. Let $\left(R^{U}, \pi^{U}\right)$ denote the pair of the interest rate and the default probability that satisfies (1) and (2) and let $\left(R^{S}, \pi^{S}\right)$ denote the pair that satisfies (1) and (8). In addition, let $\phi(\pi) \equiv(1-\pi) A+\pi(1-\theta) A$ denote the expected return on capital for unsophisticated investors that is written as a decreasing function of $\pi$, with $\phi(0)=A$.

There are three features. First, we have $R^{U}<R^{S}$ : when sophisticated investors hold the bond, the interest rate reflects the default risk fully and is higher. Second, we have $\pi^{U}<\pi^{S}$ : when sophisticated investors hold the bond, the default probability is also higher. Finally, we have $\phi\left(\pi^{U}\right)>\phi\left(\pi^{S}\right)$ : the expected return on capital for unsophisticated investors is decreasing in the default probability and is lower when sophisticated investors hold the bond.

We should have $\left(1-\pi^{S}\right) R^{S}=A>\phi\left(\pi^{S}\right)$ when (8) holds; the expected return on the bond is higher than the expected return on capital for unsophisticated investors, and then there is an incentive for unsophisticated investors to sell the claim to capital and buy the bond at some lower interest rate than $R^{S}$. The government is willing to sell the bond to investors who bid the lower interest rate. The market condition switches to (2) if unsophisticated investors can afford to buy the total debt: that is, $D \leq \varepsilon W_{0}$; then unsophisticated investors become marginal investors in the bond market. Once (2) is met, $\left(1-\pi^{U}\right) R^{U}<1+r(=A)$ should be met; there is no incentive for sophisticated investors to buy the bond. The market condition (2) then features the equilibria. On the other hand, if 
unsophisticated investors cannot afford to buy the total debt: that is, $D>\varepsilon W_{0}$, sophisticated investors become marginal investors, and (8) remains the market condition, and then the interest rate goes up, reflecting the default risk fully. Summarizing up, we can state that the equilibrium with the low interest rate survives if unsophisticated investors can afford to buy the total debt. ${ }^{15}$

It is important to note that the sustainable debt differs according to whether the equilibria are featured by either (2) or (8). Following the model, if the wealth of domestic unsophisticated investors covers the outstanding debt, the government can maintain the low interest rate and sustain the large debt. We normally evaluate sustainability by the ratio of the outstanding debt to GDP, but some measure for domestic holding also has an effect. The extent of the domestic holding of the government bonds is thought of one decisive factor for fiscal sustainability.

This finding explains why the Japan's fiscal conditions featured by the higher ratio of debt to GDP and the lower return on the government bond than other countries survive in the global economy. Domestic investors hold almost 95 percent of the debt outstanding. Additionally, large bondholders are financial intermediaries, many of which are supposed to be unsophisticated investors of the model. See Appendix A1 in details

By contrast, Italy and Spain have suffered from the high return on debt and the fiscal crises although these countries have far lower ratios of debt to GDP than Japan. ${ }^{16}$ These countries rely heavily on foreign debt, and thus the market conditions of them are featured by (8).

\section{Policy Implications}

There are several policies that are perceived to influence fiscal sustainability, including the financial market reform, growth enhancement policies, and monetary easing. In this section we argue implications of these policies.

\footnotetext{
${ }^{15}$ If sophisticated investors take an action for short selling in an attempt to drive the interest rate up, their action falls into failure so long as unsophisticated investors are willing to hold the bond. However, the self-fulfilling feature of the model allows for the successful dealing. If their action for short selling would induce the change in the expectation of unsophisticated investors from optimism to pessimism, their action could be successful.

${ }^{16}$ As of 2010, the outstanding government debts are 131 percent in Italy and 68 percent in Spain, as a proportion of GDP. Domestic investors hold 48 percent in Italy (2009) and 55 percent in Spain (the data source is OECD).
} 


\section{Financial market reform}

It is interesting to consider the financial market reform targeting some financial institutions that hold government bonds excessively. The reform is aimed for them to change the portfolio from government bond to stocks and/or foreign assets. The recent GPIF reform is a typical example. We identify the reform as decreasing the proportion of unsophisticated investors $\varepsilon$ in the model developed in the previous section. This reform is intended to guide unsophisticated investors to hold foreign assets more than government bonds.

Consider the experiment of decreasing $\varepsilon$ given the initial condition of $D<\varepsilon W_{0}$. When the reform can lead to $\varepsilon W_{0}<D$, sophisticated investors become marginal investors, and the market condition (2) is replaced by (8). The reform is followed by the rise in the interest rate.

The concern is if the market reform enhances the investor's welfare. Putting $\theta^{l}=0$ in Figure 11 illustrates the welfare analysis of this case. To make the welfare analysis clear, assume that investors invest their wealth in financial intermediaries that invest the proportion $\varepsilon$ of their wealth in unsophisticated investors and the remaining in sophisticated investors.

The consequence of the reform depends on the sustainability of the good equilibrium. If the good equilibrium is sustained, this reform makes investors better off. A difficulty, however, arises when the debt is sufficiently large that the reform makes it difficult to sustain the good equilibrium. When the debt is already large, the reform can make sustainability impossible and then investors are worse off.

An alternative way to describe the reform is to consider a setup where there are barriers that motivate investors to hold less capital and more bonds. ${ }^{17}$ Assume that a proportion $\eta$ of the return on capital is lost due to barriers. Accordingly, we can rewrite the no arbitrage between the bond and capital by

\footnotetext{
${ }^{17}$ We can consider barriers that induce agents to hold less capital and more bonds, such as the international standard for bank capital requirements, the deposit insurance, the unequal treatment of the corporate tax between bank borrowing and equity, the weak corporate governance of firms and so on.
} 


$$
(1-\pi) R=(1-\eta)\{(1-\pi) A+\pi(1-\theta) A\}
$$

We then capture the reform by a reduction in $\eta$ that motivates to make capital more attractive than bonds. The effects of the reform are qualitatively the same as those of the decline in $\theta$; the interest rate and the default probability are higher (Proposition 3 ). Following the welfare implication in Proposition 6, investors are better off so long as the good equilibrium is sustained, but are worse off otherwise.

Any financial reform that makes assets other than government bonds more attractive leads to the similar implications. The government has to perform the financial market reform by taking into account the fact that the reform makes fiscal sustainability difficult.

\section{Growth Enhancing Policies}

We identify effects of growth enhancing policies as increasing the return on capital $(A)$. Accordingly, we redefine the distribution function on tax as $F(T, A)$, which is increasing in $A$. This assumption is motivated to capture the notion that the government can collect larger taxes as the economy is rich.

A higher return on capital is followed by the higher return on the government bond, and then two opposing effects operate in terms of the investor's welfare. Investors are better off so long as the government can sustain the debt. However, they can be worse off once the government cannot sustain the debt because a higher interest rate makes debt sustainability more difficult. An additional channel operates. The collection of larger taxes enables the government to sustain the debt more likely. Summing up, growth enhancement policies can improve the welfare if the larger tax revenue improves the fiscal sustainability.

\section{Monetary Easing}

Finally we mention on the effects of the quantitative easing. As of 2014, BOJ is conducting the quantitative easing by purchasing the large scale of government bonds in the open market. Consider the experiment that the government purchases the amount $D^{M}(<D)$ of the government bonds in the market. Under the quantitative easing, the central bank participates in the market as if it is an unsophisticated investor. One effect of this policy is that the condition under which unsophisticated investors remain to be marginal 
ones changes from $D<\varepsilon W_{0}$ to $D-D^{M}<\varepsilon W_{0}$; under the new condition, the debt is less likely to be vulnerable to exogenous shocks and the good equilibrium is more likely to be sustainable.

In this model there is no direct market force under which the change in the market supply of the bond makes the interest rate low. ${ }^{18}$ However, this model embeds one possible channel through which quantitative easing leads to the decline in the interest rate. People may expect that enlarging the balance sheet of the central bank will affect the inflationary path and give rise to serious economic damages in the case of crisis. This effect can be captured by a rise in $\theta$. A rise in $\theta$ brings about the effects of lower interest rate and lower default probability, but makes the investor's welfare worse off. In short, the low interest rate reflects the possible large economic damages in case of crisis.

\section{Conclusion}

We have investigated the mechanism that explains low interest rates of Japanese government bonds. The key ingredient is the absence of any safe asset in the sense that investors have no access to any asset that hedges the fiscal risk. The poorly-functioning bond market created in this way has perverse but interesting implications on fiscal sustainability, the welfare, and policy impacts.

This paper has the potential of several directions of further research. The most interesting direction of research is to investigate the debt sustainability by introducing the developed mechanism into the general equilibrium model. The great concern is how much the low interest rate contributes to the debt sustainability in the Japanese economy.

Another interesting direction is to explore determinants of holding government bonds by financial institutions, including banks, pension funds, insurance companies. Ogawa and Imai (2013) and Sakuragawa (2013) investigate the determinants of the bond holding by Japanese major and regional banks.

Finally, we can add that the concept of the absence of safe assets will be promising, because, since the Lehman crisis, the shortage of safe assets is a great concern in the global

\footnotetext{
18 The demand function for the bond by unsophisticated investors is perfectly elastic with respect to the interest rate, and thus given $D<\varepsilon W_{0}$, the change in the supply never changes the interest rate.
} 
economy.

\section{Appendix 1: Some features of the JGB market}

Table A1 illustrates several features of the JGB market, as of 2012. The column 2 depicts the market share of individual institutions. Financial institutions that are owned or regulated by the government account for 76.1 percent of the total national debt. Among them, the central bank, public financial institutions, and public pension funds, all of which are owned by the government, totally account for 38.2 percent. ${ }^{19}$ Private banks and private insurance companies, both of which are regulated by the government, account for 37.9 percent.

Columns 3 and 4 depict some information on asset portfolio by each institution. All of domestic financial institutions hold smaller foreign assets relative to the national bond. Reference at the bottom of Table A1 reveals how the portfolio of government-related financial institutions is biased toward government bonds.

For example, financial institutions for agriculture, forestry, and fisheries hold the almost equal portfolio for national bonds and foreign assets. By contrast, private banks and public financial institutions hold more government bonds and less foreign assets. These intermediaries are comparable in that their activities are regulated by capital requirements, but they have different portfolio. In addition, the similar argument holds between public and private pension funds; public pension funds hold more government bonds and less foreign assets than private pension funds.

(Insert Table A1)

These observations suggest that there is a significant degree of home bias in the portfolio among several large holders of government bonds. Regulations and misguided governance are perceived to have induced them to hold government bonds excessively, and to behave as if they are isolated from foreign markets. ${ }^{20}$

${ }^{19}$ Public financial institutions include Japan Postal Bank and Japan Post Insurance.

${ }^{20}$ Japanese insurance companies are regulated to eliminate the maturity mismatch of the balance sheet following the solvency margin ratio and induced to hold long-term public bonds excessively. Japan Postal Bank is privatized in 2005, but still has the weak governance structure in the asset portfolio, and hold more than 80 percent of public debt in the total asset. Due to the weak governance structure, GPIF invests more than half of assets in public debt and is now under reform. 


\section{Appendix 2: Proofs of Propositions 2 and 3}

We differentiate $\Omega(R) \equiv R\{1-F(R D)\}+\theta A F(R D)-A=0$ totally and get $d R=-\frac{\Omega_{\theta}}{\Omega_{R}} d \theta-\frac{\Omega_{D}}{\Omega_{R}} d D$, where note that $\Omega_{R} \equiv \frac{\partial \Omega}{\partial R}=\{1-F(R D)\}-f(R D) D(R-\theta A)>0$ at the good equilibrium, $\Omega_{\theta} \equiv \frac{\partial \Omega}{\partial \theta}=A F(R D)>0$, and $\Omega_{D} \equiv \frac{\partial \Omega}{\partial D}=-f(R D) R(R-\theta A)<0$ from (3). We finally obtain

(A-1) $\quad d R=-\frac{A F(R D)}{\{1-F(R D)\}-f(R D) D(R-\theta A)} d \theta+\frac{f(R D) R(R-\theta A)}{\{1-F(R D)\}-f(R D) D(R-\theta A)} d D$

As the default cost measure $\theta$ goes up, interest rate $R$ decreases at the good equilibrium. As the amount of outstanding debt $D$ goes up, interest rate $R$ increases at the good equilibrium.

We next differentiate (1) totally, and get

$$
d \pi=F_{R} d R+F_{D} d D
$$

where $F_{R} \equiv \frac{\partial F}{\partial R}=f(R D) D>0$ and $F_{D} \equiv \frac{\partial F}{\partial D}=f(R D) R>0$.

Inserting (A-2) into (A-1), we obtain

$d \pi=-\frac{A F(R D) f(R D) D}{\{1-F(R D)\}-f(R D) D(R-\theta A)} d \theta+f(R D) R\left[\frac{(R-\theta A) f(R D) D}{\{1-F(R D)\}-f(R D) D(R-\theta A)}+1\right] d D$

As the default cost measure $\theta$ goes up, the default probability $\pi$ declines at the good equilibrium. As the amount of outstanding debt $D$ goes up, the default probability $\pi$ increases at the good equilibrium. Q.E.D.

\section{Appendix 3: Proof of Proposition 4:}

To prove Proposition 4 , it is enough to check the sign of $\frac{\partial(d \log R / d \log D)}{\partial \theta}$, where $\frac{d \log R}{d \log D}\left(\equiv \frac{d R}{d D} \cdot \frac{D}{R}\right)$ is the debt elasticity of interest rate.

From (A-3) with $d \theta=0$, we get 
(A-4) $\frac{d R}{d D}=\frac{f(R D) R(R-\theta A)}{\{1-F(R D)\}-f(R D) D(R-\theta A)}$,

and

(A-5) $\frac{d \log R}{d \log D}=\frac{f(R D) D(R-\theta A)}{\{1-F(R D)\}-f(R D) D(R-\theta A)}$.

Using the property that $R$ is decreasing in $\theta$ that is seen from Proposition 3, we get (A-6) $\frac{\partial(d \log R / d \log D)}{\partial \theta}$

$=\frac{D}{[\{1-F(R D)\}-f(R D) D(R-\theta A)]^{2}}$

$\times\left[\{1-F(R D)\}\left[\left\{f^{\prime}(R D) D(R-\theta A)+f(R D)\right\} \frac{\partial R}{\partial \theta}-f(R D) A\right]+\{f(R D)\}^{2} D(R-\theta A) \frac{\partial R}{\partial \theta}\right]$.

If $f^{\prime}(R D) \geq 0$, we obtain $\frac{\partial(d \log R / d \log D)}{\partial \theta}<0$ at the good equilibrium. Thus, the sensitivity of a change in the outstanding debt to the interest rate is smaller as $\theta$ is high if $f^{\prime}(R D) \geq 0$. Q.E.D.

\section{Appendix 4: Proof of Proposition 6}

First of all, we calculate $\hat{R}=\arg \max \Omega(R)$. From the net return function $\Omega(R) \equiv R\{1-F(R D)\}-A\{1-\theta F(R D)\}$, we obtain the maximum interest rate as $\hat{R}=\frac{\theta A D+\bar{T}}{2 D}$.

Next we obtain $D=\phi(\theta)$. Since $\Omega(\hat{R}(\theta, D), \theta, D)=0$ implies $\frac{1}{4 D \bar{T}}\left\{(\theta A D+\bar{T})^{2}-4 A D \bar{T}\right\}=0$, or $D=\frac{\left\{(2-\theta) \pm \sqrt{(2-\theta)^{2}-\theta^{2}}\right\} \bar{T}}{\theta^{2} A}$. If we set $D_{1}=\frac{\left\{(2-\theta)-\sqrt{(2-\theta)^{2}-\theta^{2}}\right\} \bar{T}}{\theta^{2} A}$ and $D_{2}=\frac{\left\{(2-\theta)+\sqrt{(2-\theta)^{2}-\theta^{2}}\right\} \bar{T}}{\theta^{2} A}$, we obtain $\frac{\partial D_{1}}{\partial \theta}>0$ and $\frac{\partial D_{2}}{\partial \theta}<0$. Thus the stable solution should be $D_{1}$, and we define $D=\frac{\left\{(2-\theta)-\sqrt{(2-\theta)^{2}-\theta^{2}}\right\} \bar{T}}{\theta^{2} A} \equiv \phi(\theta)$, where $\phi^{\prime}(\theta)=\frac{\phi(\theta)\left\{2-\sqrt{(2-\theta)^{2}-\theta^{2}}\right\}}{\theta \sqrt{(2-\theta)^{2}-\theta^{2}}}(>0)$. 
Finally we obtain $\frac{d \hat{R}}{d \theta}=-\frac{1}{\Omega_{R R}}\left(\Omega_{R \theta}+\Omega_{R D} \phi^{\prime}\right)$. From $\Omega_{R R}=-\frac{2 D}{\bar{T}}, \Omega_{R \theta}=\frac{A D}{\bar{T}}$ and $\Omega_{R D}=-\frac{1}{\bar{T}}(2 \hat{R}-\theta A), \frac{d \hat{R}}{d \theta}=\frac{1}{2 D^{2}}\left(A D^{2}-\bar{T} \phi^{\prime}\right)=\frac{-A}{\sqrt{(2-\theta)^{2}-\theta^{2}}}(<0)$. Furthermore, the elasticity is $\frac{\theta}{\hat{R}} \frac{\partial \hat{R}}{\partial \theta}=\frac{\sqrt{(2-\theta)^{2}-\theta^{2}}-(2-\theta)}{\sqrt{(2-\theta)^{2}-\theta^{2}}-2(1-\theta)}$. Q.E.D.

\section{Literature}

Abreu, D., Brunnermeier, M., 2003. Bubbles and Crashes. Econometrica 71, 173-204

Ahearne, A. G., Griever, W. L., Warnock, F. E., 2004. Information costs and home bias: an analysis of U.S. holdings of foreign equities. Journal of International Economics 62, 313-336

Arellano, C., 2008. Default risk and income fluctuations in emerging economies. American Economic Review 98(3), 690-712

Broda, C., Weinstein, D.E., 2005. Happy News from the Dismal Science: Reassessing the Japanese Fiscal Policy and Sustainability. In: Takatoshi, I., Patrick, H., Weinstein, D.E., (Eds.). Reviving Japanese Economy: MIT Press, 39-78

Calvo, A.G., 1988. Servicing the Public Debt: The Role of Expectations. American Economic Review 78, 647-61

Cohen, D., Sachs, J., 1986. Growth and External Debt under Risk of Debt Repudiation. European Economic Review 30(3), 529-60

Cole, H., Kehoe, T., 2000. Self-Fulfilling Debt Crises. Review of Economic Studies 67, 91-116

Dahlquist, M., Pinkowitz, L., Stulz, R.M., Williamson, R., 2003. Corporate governance and home bias. Journal of Financial and Quantitative Analysis 38, 87-110

Dekle, R., 2005. Understanding Japanese Saving: Does Population Aging Matter? : Routledge Curzon. 
Doi, T., Ihori, T., 2003. Sustainability of Government Deficits in Japan: Including Trends in Local Government Finance. In: Yoshino, N., Inukai, S., Tamaki, N., (Eds.). Enhancing Market Functions in Japan. : Keio University Press.

Doi, T., Hoshi, T., Okimoto, T., 2011. Japanese Government Debt and sustainability of Fiscal Policy. Journal of Japanese International and Economies 25(4), 414-433

De Long, J.B., Shleifer, A., Summers, L.H., Waldmann, R.J., 1990. Positive Feedback Investment Strategies and Destabilizing Rational Speculation. The Journal of Finance 45(2), 379-395

Fidora, M., Fratzscher, M., Thimann, C., 2007. Home bias in global bond and equity markets: The role of real exchange rate volatility. Journal of International Money and Finance 26(4), 631-655

Glassman, D.A., Riddick, L.A., 2001. What causes home asset bias and how should it be measured? Journal of Empirical Finance 8, 35-54

Hansen, G.D., Imrohoroglu, S., 2013. Fiscal Reform and Government Debt in Japan: A Neoclassical Perspective. NBER Working Paper No. 19431

Harrison, J.M., Kreps, D., 1978. Speculative investor behavior in a stock market with heterogeneous expectations. Quarterly Journal of Economics 92, 323-336

Hoshi, T., Ito, T., 2013. Is the Sky the Limit? Can Japanese Government Bonds Continue to Defy Gravity? Asian Economic Policy Review 8(2), 218-247

Ihori, T., Kato, R., Kawade, M., Bessho, S., 2007. Public Debt Policy and Economic Growth in An Aging Japan. In: Kaizuka, K., Krueger, A., (Eds.). Tackling Japan's Fiscal Challenges: Strategies to Cope with High Public Debt and Population Aging. IMF: Palgrave.

Ogawa, K., Imai, K., 2013. Why Do Financial Institutions Hold Government Bonds?: The Case of Japan. mimeo.

Portes, R., Rey, H., 2005. The determinants of cross-border equity flows. Journal of International Economics 65, 269-296

Reinhalt, C.M., Rogoff, K.S., 2010. This Time is Different. Princeton University Press. Romer, D., 2001. Advanced Macro Economics, Second Edition. McGraw-Hill Higher Education.

Sakuragawa, M., Hosono, K., 2010. Fiscal Sustainability of Japan: A Dynamic Stochastic General Equilibrium Approach. The Japanese Economic Review 61(4), 517-537 
Sakuragawa, M., Hosono, K., 2011. Fiscal Sustainability in Japan. Journal of Japanese International and Economies 25(4), 434-446

Sakuragawa, Y., 2013. Why do Japanese banks hold a large amount of government bonds? mimeo.

Scheinkman, J.A., Xiong, W., 2003. Overconfidence and speculative bubbles. Journal of Political Economy 111, 1183-219

Uribe, M., 2006. A fiscal theory of sovereign risk. Journal of Monetary Economics 53, $1857-75$ 
Table A1: Features of the JGB market (2012)

\begin{tabular}{|l|c|c|c|}
\hline & share & national debt/assets & foreign assets/assets \\
\hline Central bank & $11.6 \%$ & $53.3 \%$ & $2.4 \%$ \\
\hline Private banks & $21.5 \%$ & $11.6 \%$ & $4.5 \%$ \\
\hline Private insurance & $16.4 \%$ & $35.7 \%$ & $17.0 \%$ \\
\hline $\begin{array}{l}\text { Public financial } \\
\text { institutions }\end{array}$ & $17.9 \%$ & $31.0 \%$ & $2.8 \%$ \\
\hline Public pension funds & $8.7 \%$ & $33.4 \%$ & $16.9 \%$ \\
\hline Households & $3.0 \%$ & $1.5 \%$ & $0.5 \%$ \\
\hline Overseas & $4.4 \%$ & $7.6 \%$ & - \\
\hline Others & $16.5 \%$ & - & - \\
\hline
\end{tabular}

Reference

\begin{tabular}{|l|c|c|c|}
\hline $\begin{array}{l}\text { Financial institutions } \\
\text { for agriculture, } \\
\text { forestry, and fisheries }\end{array}$ & $3.1 \%$ & $10.4 \%$ & $11.0 \%$ \\
\hline Private pension funds & $3.5 \%$ & $22.7 \%$ & $20.1 \%$ \\
\hline
\end{tabular}

(Data source: BOJ) 
Figure 1: The nominal interst rate rate and the government debt to GDP ratio

(2000-2012)

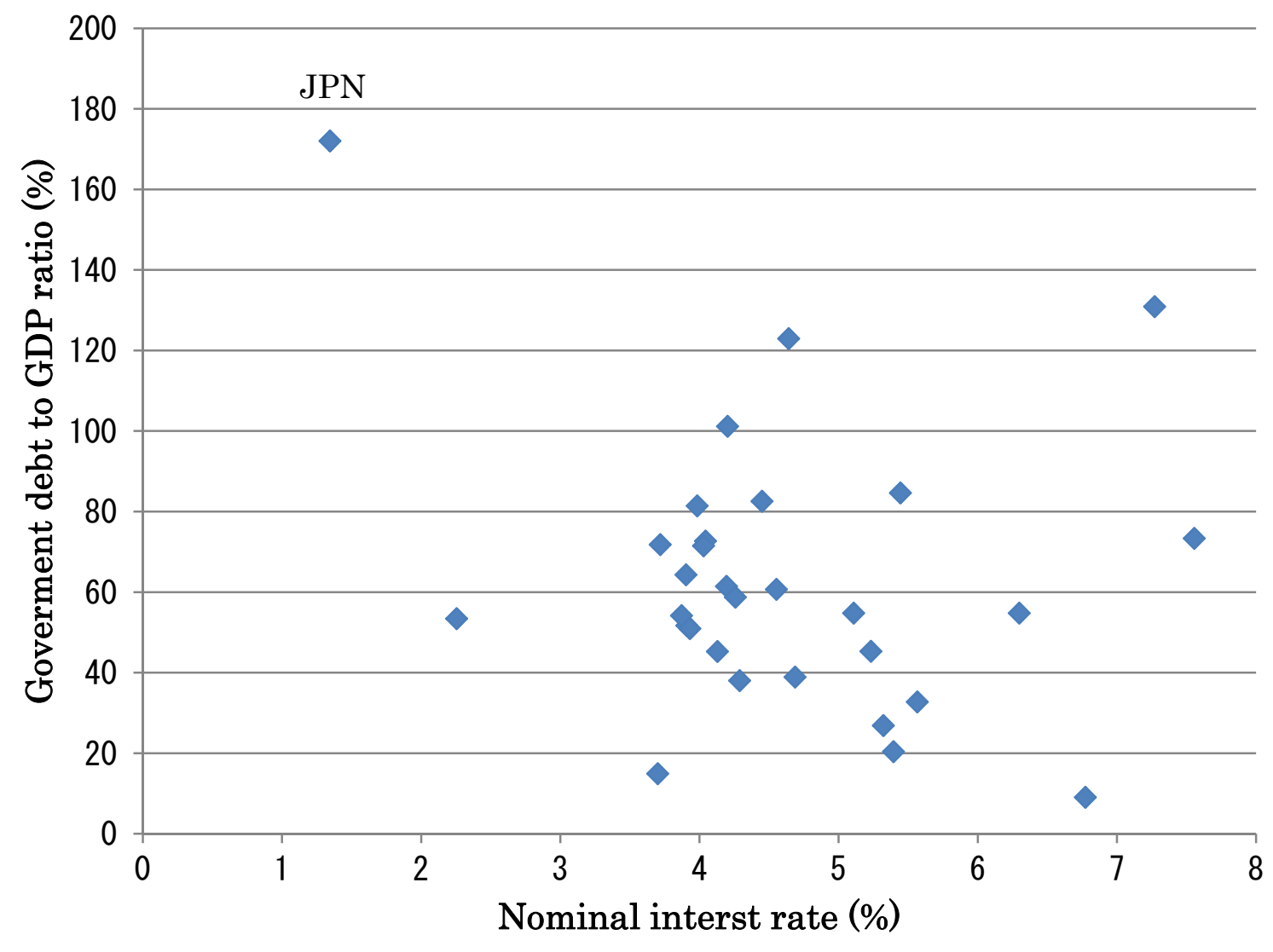

(Data source: OECD and IMF) 
Figure 2: Nominal returns on the 10 years government bond

for 4 countries

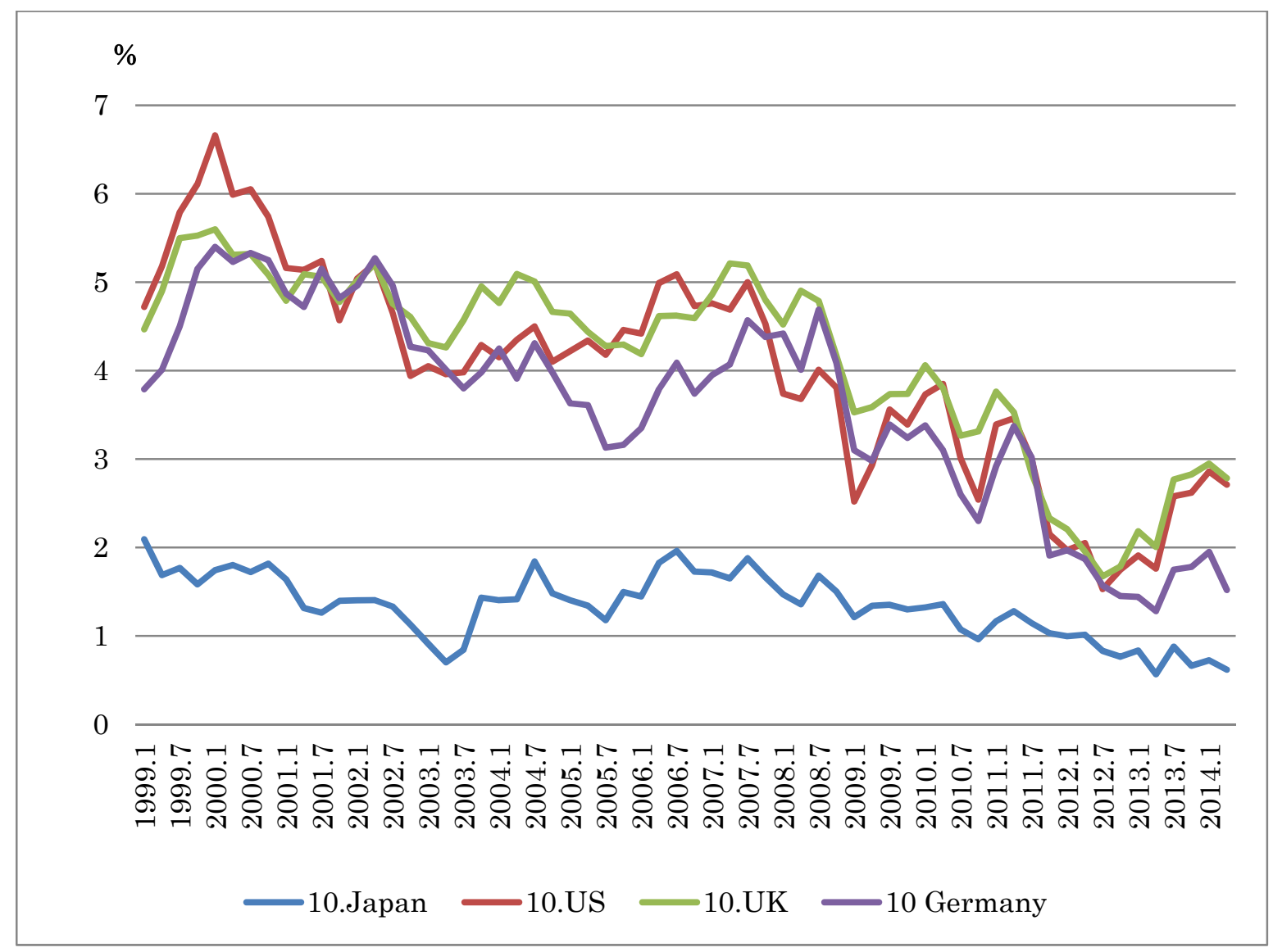

(Data source: Bank of Japan, the FRB, Bank of England, and Deutsche Bundesbank) 
Figure 3: Locus of government condition

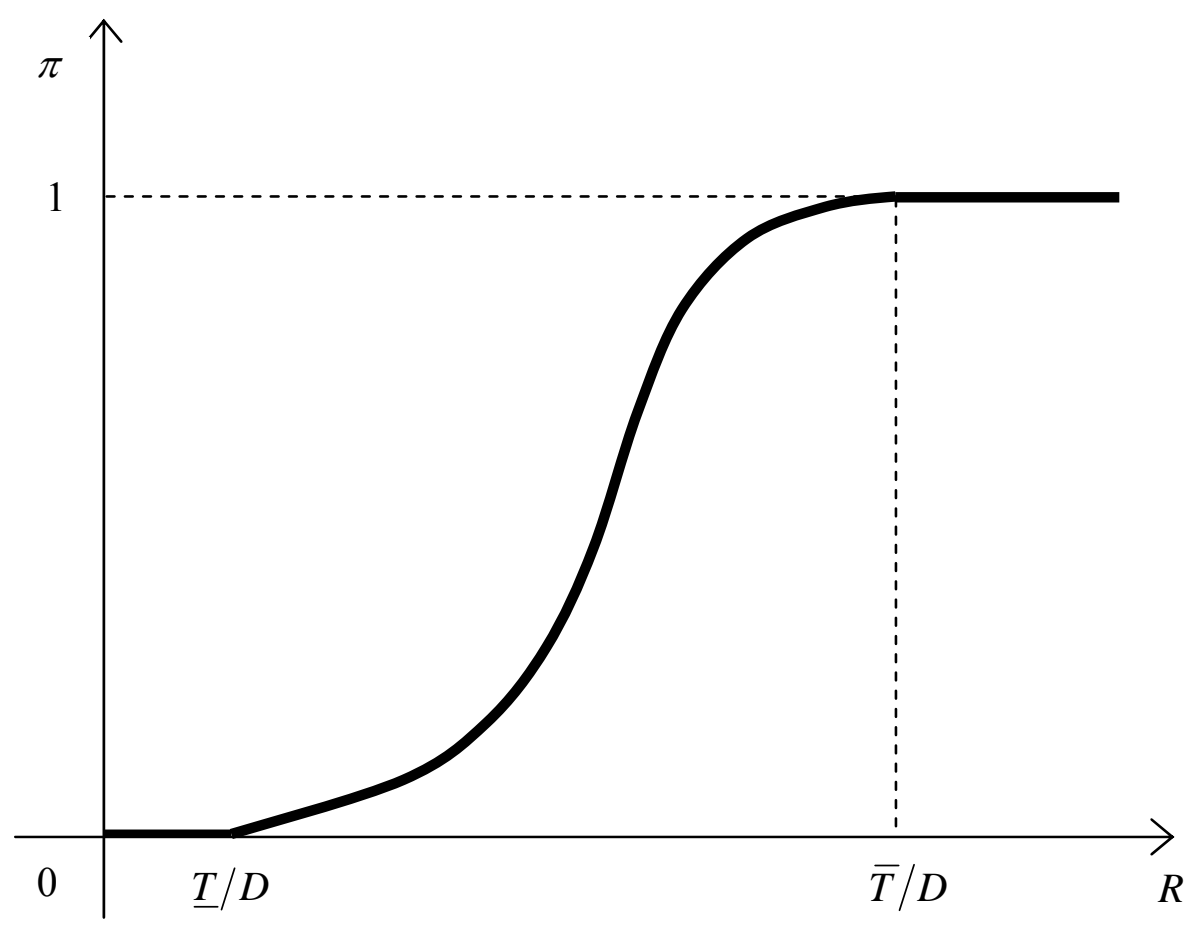


Figure 4 : The net return function on the bond

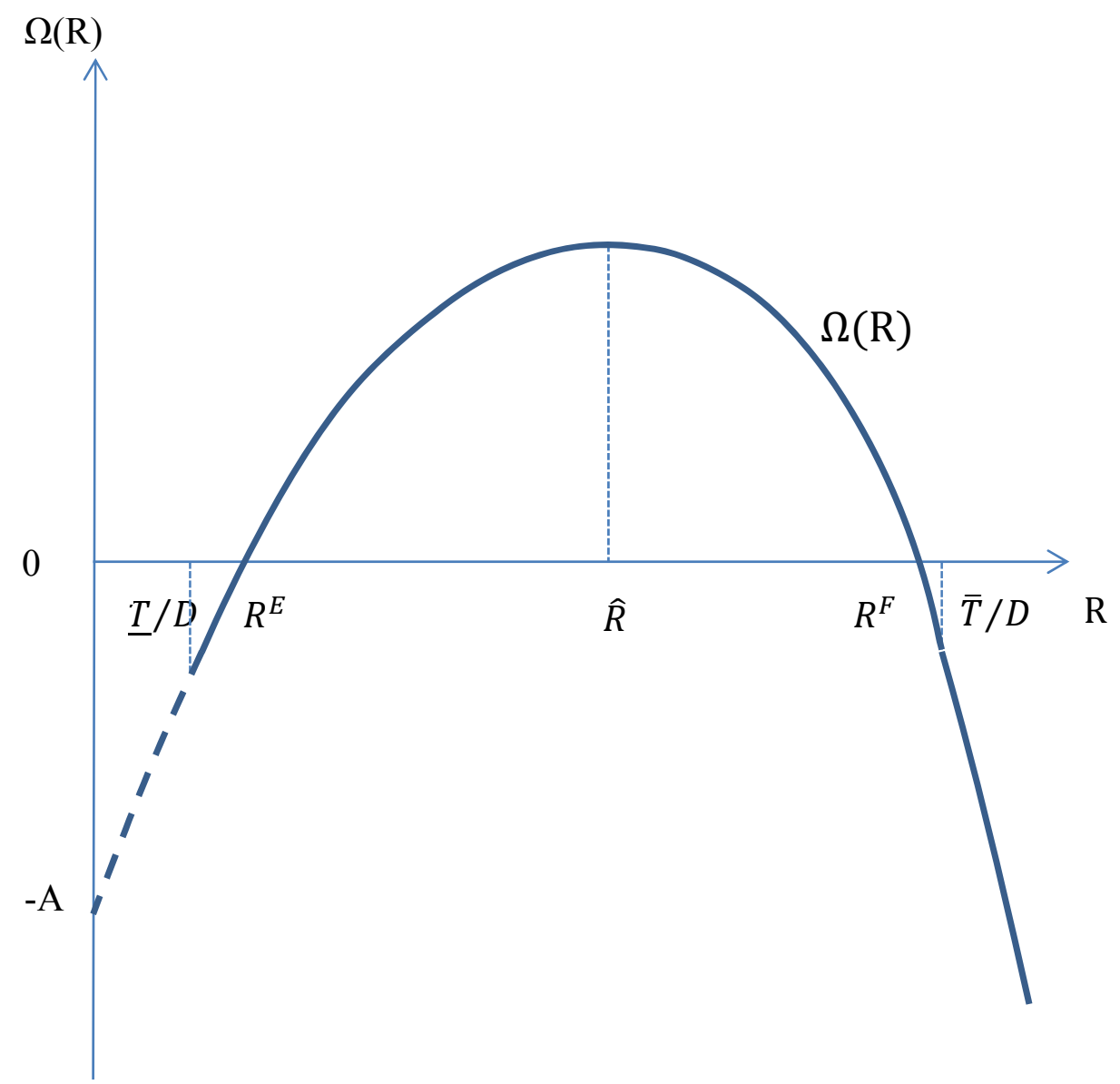


Figure 5: Locus of market condition

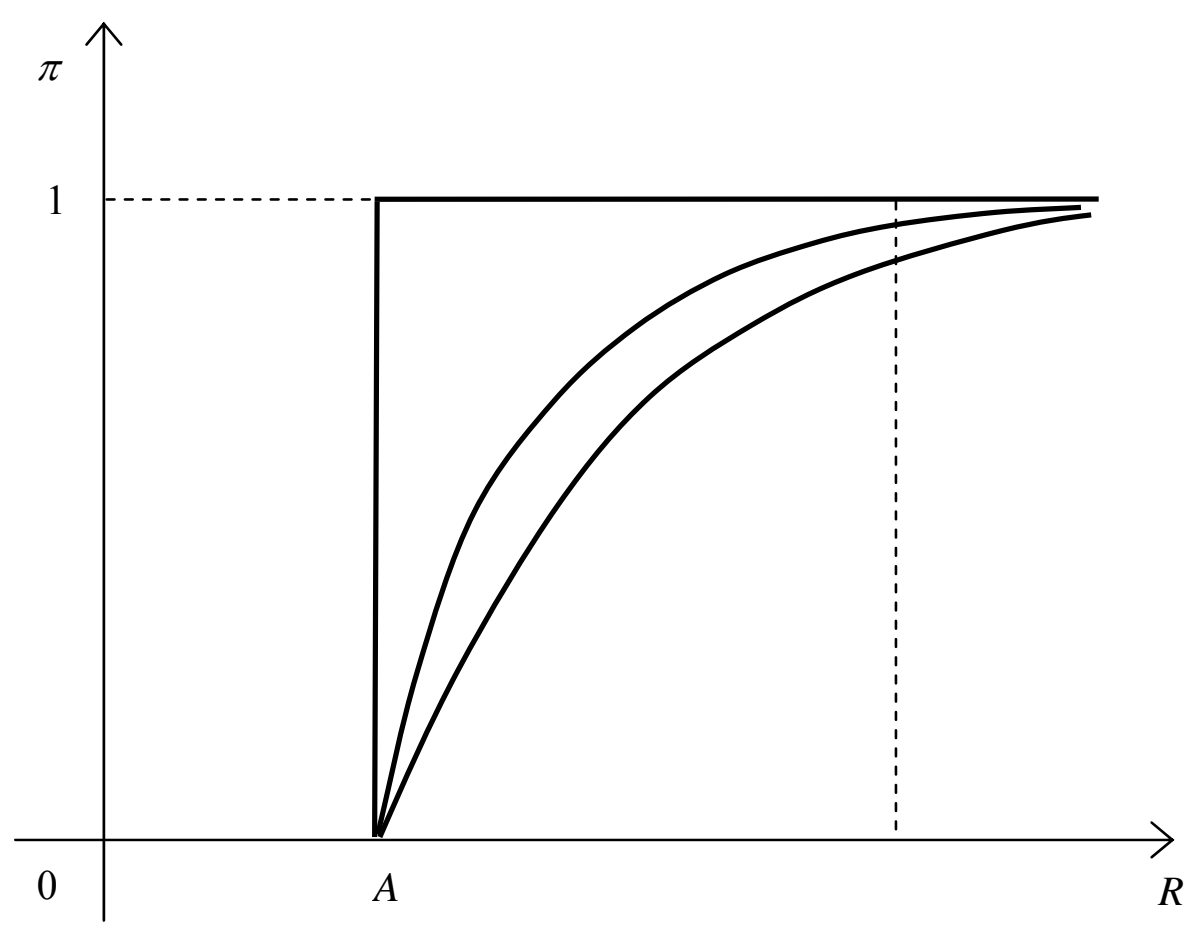


Figure 6: Multiple equilibria

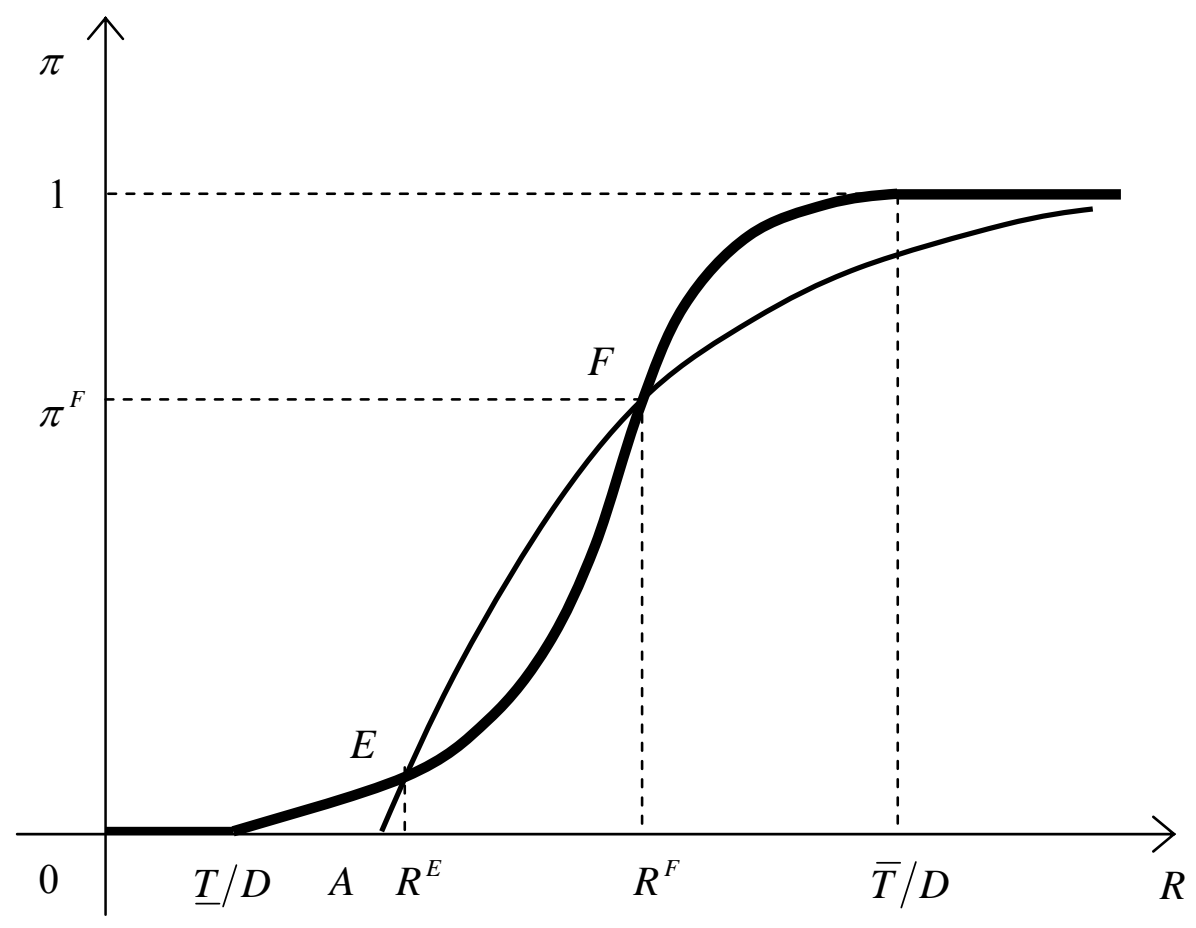


Figure 7: Change in $D$

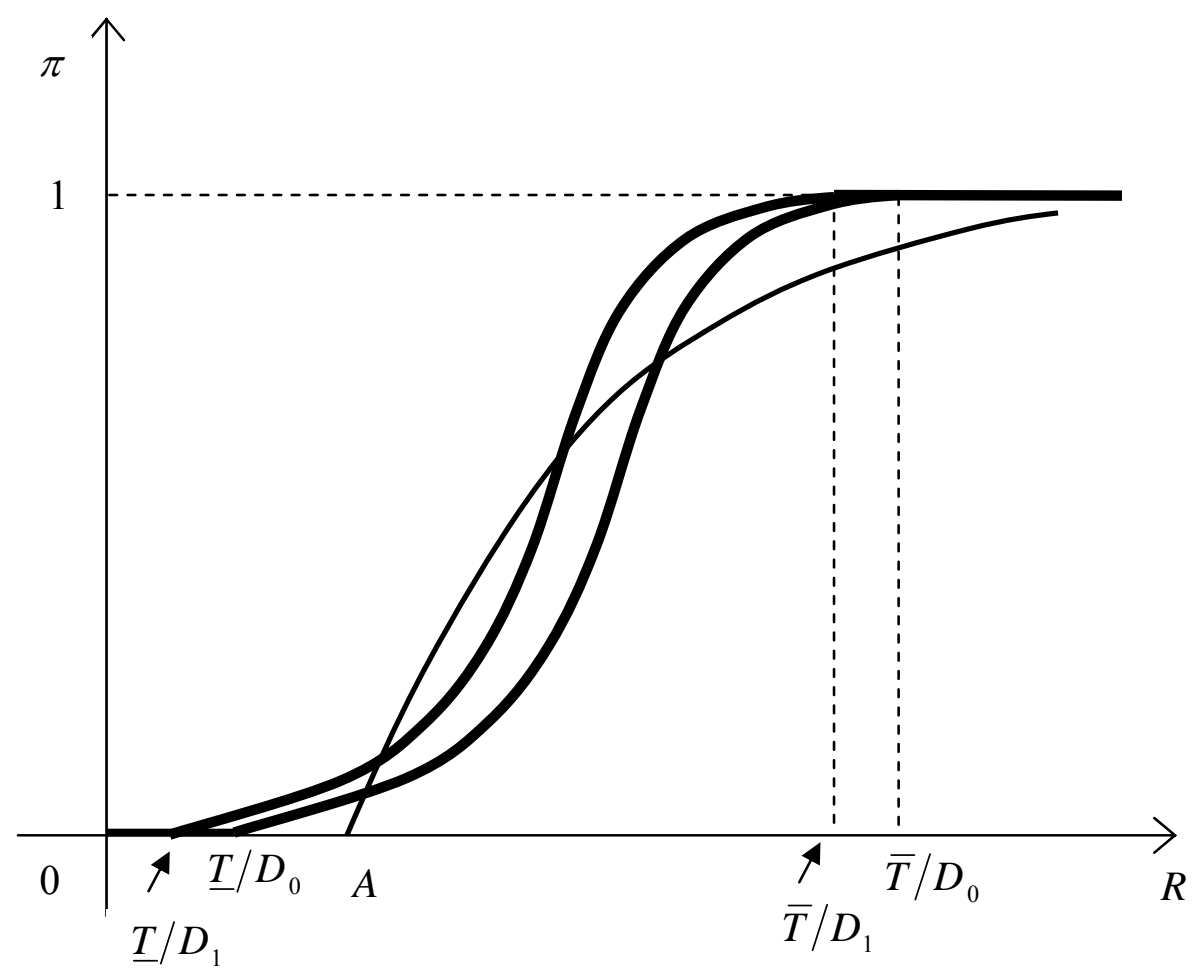


Figure 8: Change in $\theta$

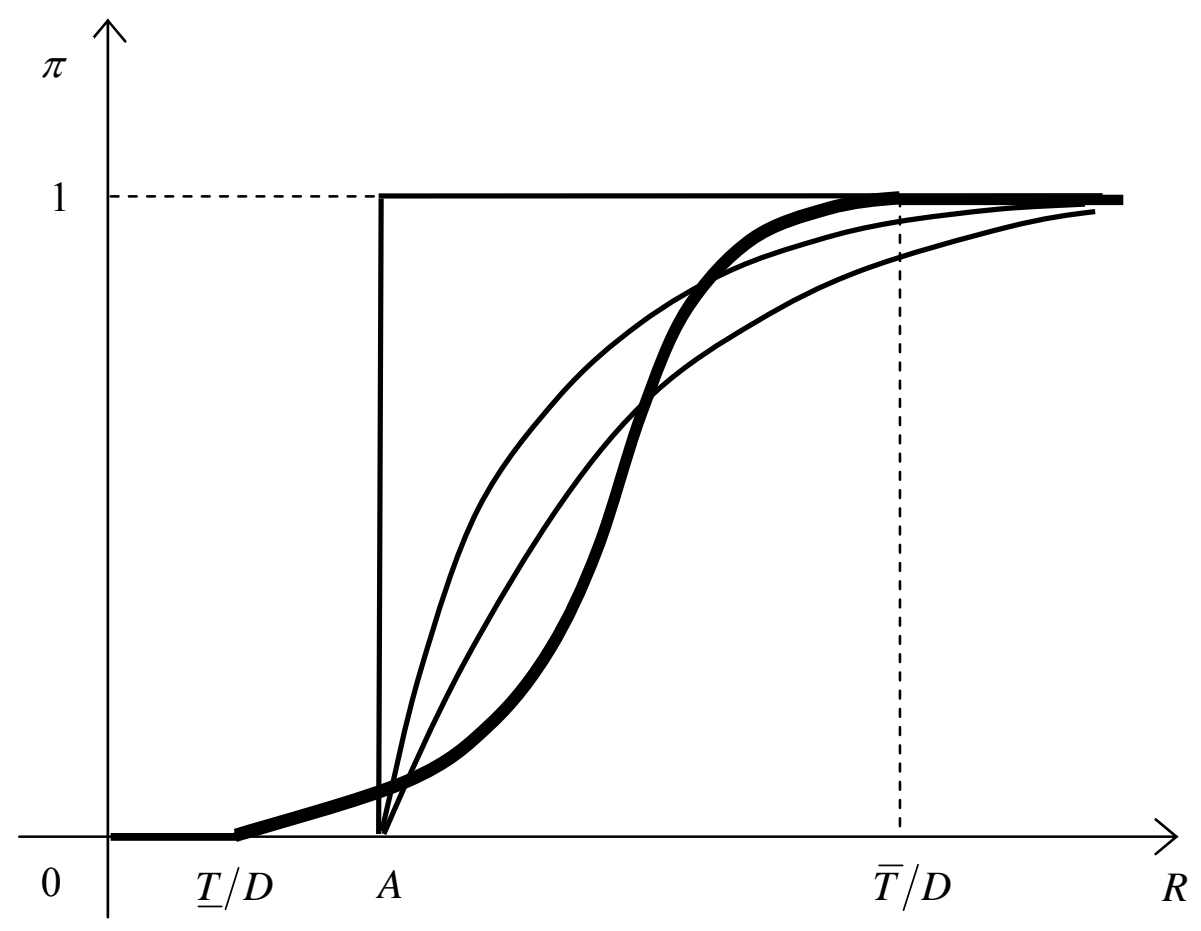


Figure 9 : The threshold interest rate

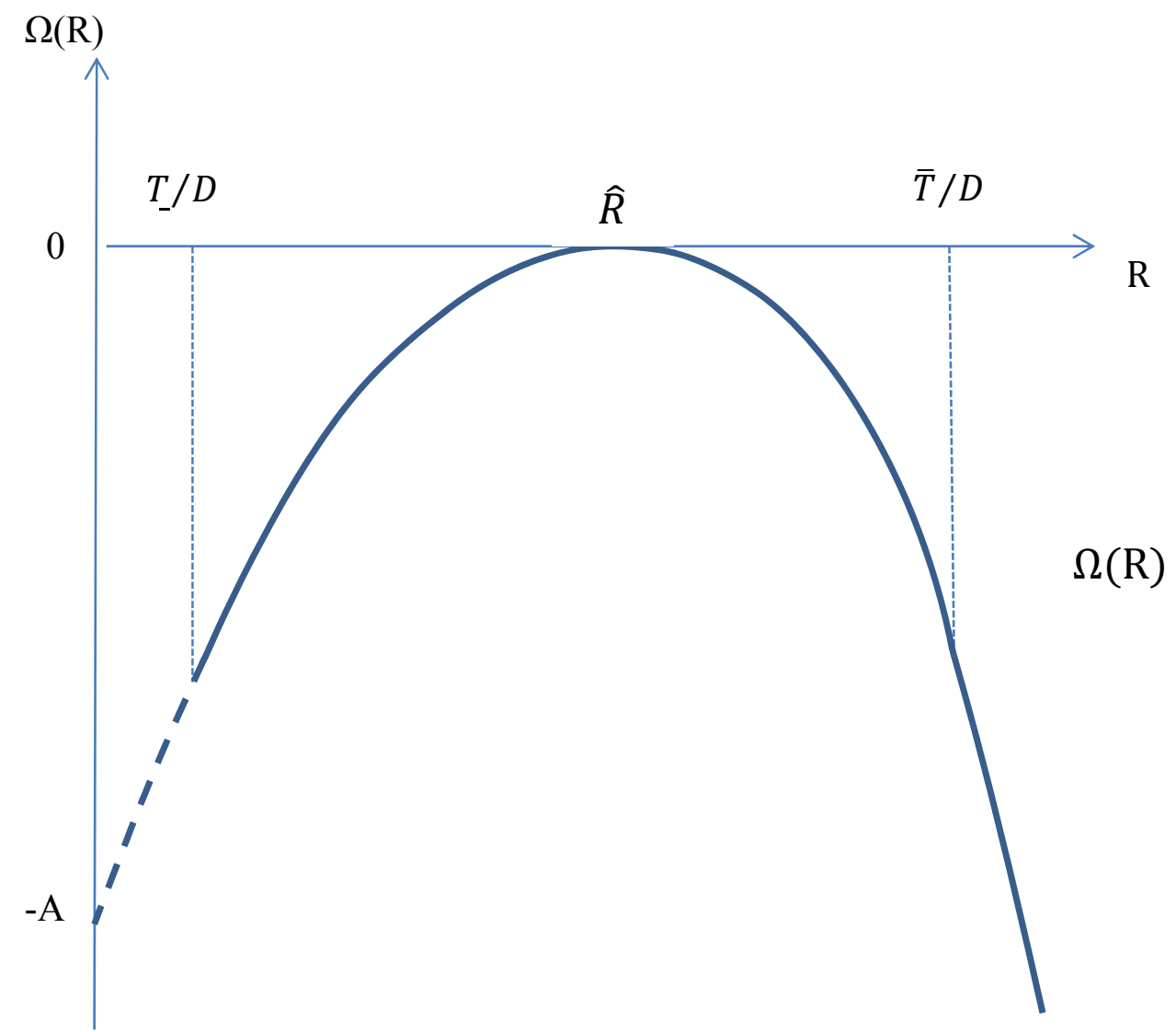


Figure 10 : The welfare function and the net return function

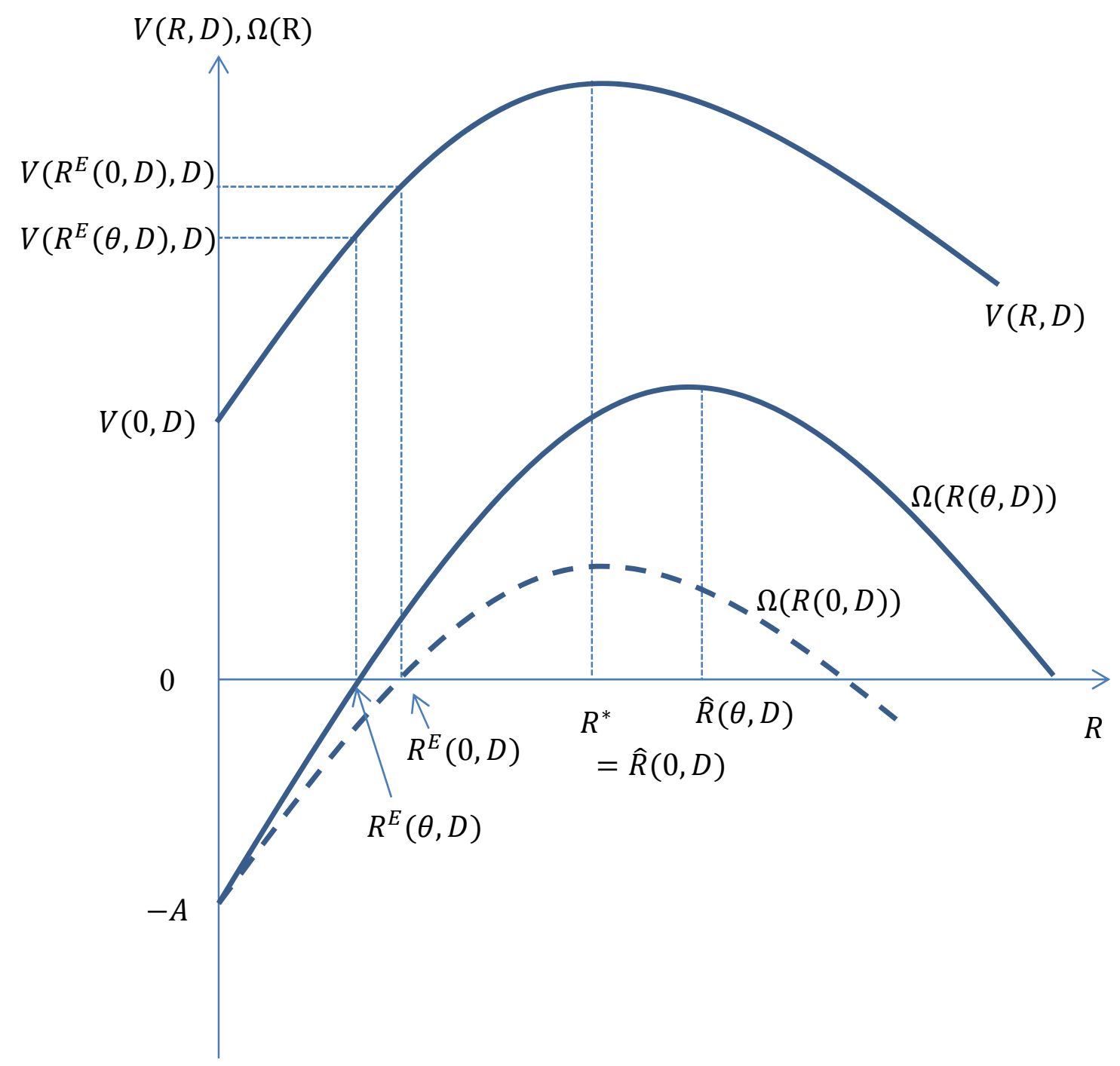


Figure 11: Welfare Analysis in terms of $\theta$

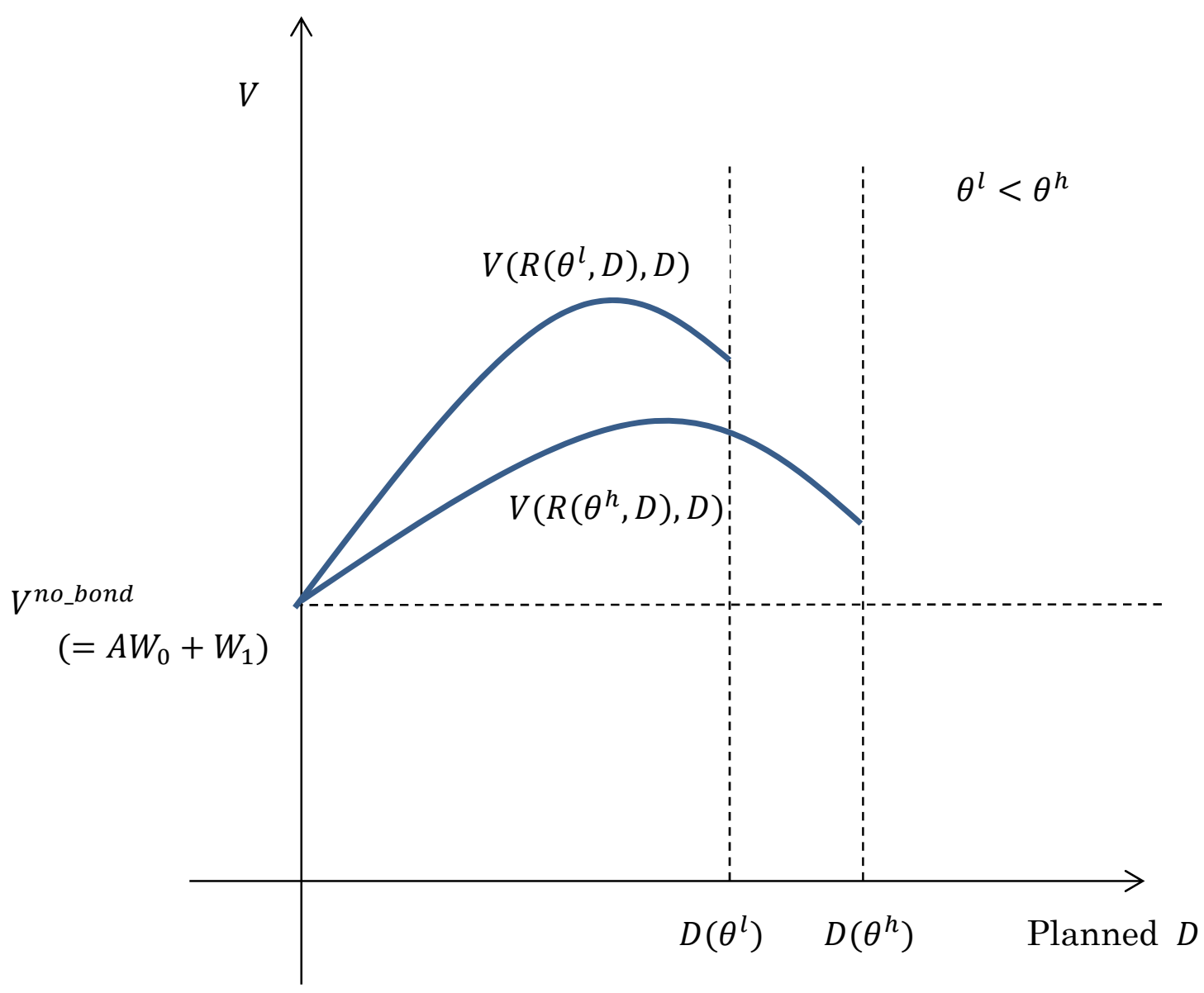

